\title{
ACADEMIC CONTINUITY OF CLINICAL TRAINING IN POSTGRADUATE MEDICAL EDUCATION AMID THE PANDEMIC
}

\author{
Pérez Jiménez M*, Dávila Rivas A, Félix Arce C, Padilla LA and \\ Cordero-Díaz MA \\ Tecnologico de Monterrey, Escuela de Medicina y Ciencias de la Salud, Mexico
}

\begin{abstract}
The pandemic has posed many challenges for the academic continuity of clinical training. The social responsibility of universities and the professionalism of physicians inspired residents on taking the leadership in the front line of COVID-19. Their direct involvement in patient care required the establishment of protocols to offer mentoring and support services for self-care and mental health strategies to prevent burnout. The objective of this study was to describe the design and implementation of a comprehensive strategy to transform the Multicentric Program of postgraduate medical education in northern Mexico to continue academic and clinical training activities amid the pandemic. The participants in this study include six training centers which represent 290 physicians in 17 medical specialties programs. The results of the designed strategy focus on three specific activities: 1) offering formal curricular elements through online platforms and mobile devices, 2) adaptative clinical training for the residents participating directly in SARS-Cov2 patient care, and 3) specific training on COVID-19 for all participants on patient safety protocols and use of protective equipment. All 17 programs achieved academic continuity by the use of digital platforms. The protection and safety of the educational community were privileged with the purpose of training by providing residents specific safety training on COVID-19, personal protection equipment, periodical PCR testing and by the vaccination strategy. The responsibility and responsiveness of educational institutions to address the challenges to continue the clinical training during the health crisis will significantly affect the educational results and preparedness of the next generation of health professionals. The commitment of universities should be beyond academic continuity or sharing content online, it should address as well self-care and wellbeing strategies that could provide graduates with the skills that are essential to thrive in the current pandemic.
\end{abstract}

Keywords: higher education, educational innovation, postgraduate medical education, residents' education, COVID-19

\section{Introduction}

It is the end of an era as we knew it: the era of the pre-SARS-Cov2 postgraduate medical education. A brave new world has begun amid the pandemic. The fundamental purpose of residency programs to deliver educational opportunities that shape resident physicians' careers has been challenged by the COVID-19 pandemic. Furthermore, a critical question has arisen: will COVID-19 catalyze a postgraduate medical education transformation? 
Since early 2020, the ongoing novel coronavirus pandemic has impacted, even in some cases halted, many activities traditionally offered by programs to fulfill the mission of residents' education. Clinical rotations and professional development activities, including those focused on individual trainees' interests, have been displaced by intervening patient care needs mainly from the SARS-Cov2 pandemic (Vande Vusse et al. 2021).

\section{The Hidden Curriculum of the COVID-19 Pandemic}

Cancellation of routine ambulatory care visits, hospitalizations, and elective surgeries has dramatically reduced overall clinical activity and consequently the learning opportunities for trainees. Also, the surge of COVID-19 patients has overwhelmed available specialists, and as a result and in order to provide patient care, many academic health centers have deployed residents and fellows across the usual specialty boundaries. The virus disruption to postgraduate medical education was an unexpected change-agent that has provided a learning opportunity to understand how best to respond to the needs of delivering educational opportunities to residents and to develop an educational reform (Goldhamer et al. 2020).

The COVID-19 pandemic has been overwhelming, frightening, and even catastrophic, but it has also been a rich educational opportunity, full of teachable and significant moments, with its own hidden curriculum (Botros and Cooper, 2020). Online lectures, virtual meetings with trainees, and outpatient telehealth has been widely embraced. It quickly became part of the new pandemic normal. Clinicianeducators continued to work with patients and teach individual trainees daily, despite the risk of contagion. An important -and disruptive- legacy of this pandemic will be how trainees and attending physicians from different specialties were needed to practice in areas entirely outside of their clinical discipline. Residents and fellows have been hailed as heroes that risk their lives to provide patient care while adapting to changing practice patterns, often daily. Many lessons can be learned from the operation of these past months and the final analysis of this pandemic's educational significance has yet to be written, as Botros and Cooper (2020) have emphasized, with the hope that this dark time will help the graduate medical education community to recognize what was newly learned and what was always in plain sight.

\section{Challenges for postgraduate medical education}

The pandemic has posed many challenges for the academic continuity of clinical training. The social responsibility of universities and the professionalism of physicians inspired residents on taking the lead in the front line of the COVID-19 pandemic. Their direct involvement in patient care required the establishment of mentoring protocols and support services for self-care. The importance of establishing mental health strategies and preventing burnout in residents is a shared responsibility between educational institutions and hospitals (Valdez-García et al. 2020).

Valdez et al (2020) proposed a guideline as an action plan to face the expansion of COVID-19. First, the protection and safety of the educational community should be privileged with the purpose of training. Secondly, academic continuity should be performed with distance education, intensive use of technology, digital resources, and the application of virtual simulation scenarios, considering stages of preparation, design, implementation, and evaluation. A third component is fostering the communication and emotional follow-up of the academic community to mitigate anxiety, uncertainty, 
and loneliness for students, teachers, and support staff. Finally, to underscore that social responsibility is part of the medical and health sciences mission.

Byrne et al (2021) emphasized that the Accreditation Council for Graduate Medical Education (ACGME) has recognized clinician well-being as a major challenge in health care and stressed the importance of resident and faculty safety and well-being. As the pandemic spread, of significant concern to the ACGME is the threat to the safety and well-being of residents and faculty in the context of the entire health care workforce (Accreditation Council for Graduate Medical Education, 2020). The leaders of the National Academy of Medicine Action Collaborative on Clinician WellBeing, which includes the ACGME, raised concerns of a parallel pandemic amid the initial surge of COVID-19 cases, with an emphasis on psychological safety. These well-being concerns continue to be compounded by the threat to physical safety occurring on the frontlines. To adapt to the new environment, the ACGME issued directives to the graduate medical education (GME) community and emphasized the need for personal protective equipment (PPE), calling on national leaders to ensure the entire health care workforce has sufficient access to appropriate PPE (Byrne et al. 2021). The responsibility and responsiveness of educational institutions to address these challenges and their impact on educational results, resident and fellow physicians well-being, and patient care are essential in the current pandemic (American Medical Association, 2020).

The objective of this paper is to describe the design and implementation of a comprehensive strategy to transform the Multicentric Program of postgraduate medical education in northern Mexico to continue academic and clinical training activities amid the pandemic.

\section{Methods}

The research question was what actions must be taken to guarantee academic continuity and clinical training in a Multicentric Program of postgraduate medical education amid the COVID-19 pandemic?

A comprehensive strategy to transform the Multicentric Program of postgraduate medical education to continue academic and clinical training activities amid the pandemic was designed and implemented during 2020 and 2021. The participants in this study include six training centers which represent 290 physicians in 17 medical specialties programs.

The key elements of the designed comprehensive strategy focus on three specific activities (Figure 1):

1. Online academic sessions to maintain the formal curricular elements through educational platforms and electronic devices, the main challenges were the digital transformation of all courses and promoting an online education faculty development program;

2. Adaptative clinical training, including residents participating both in non-Covid-19 areas and directly in SARS-Cov2 patient care, with the appropriate patient safety protocols, use of personal protective equipment and duty hours regulations, to meet the learning objectives, such as opportunities for clinical training under direct supervision according to the level of development of professional competencies, strict adherence to the regulations of frequency and hours on-call, as well as rest periods; 
3. Specific training related to the COVID-19 pandemic for patient care, all residents received training on COVID-19, patient safety protocols, and use of protective equipment.

Professionalism and university social responsibility actions were also implemented as part of the comprehensive strategy (Figure 1):

- Residents' leadership in the education of health personnel and the general population.

- Residents' mentoring and support services as strategies for self-care, well-being, mental health care and burnout syndrome prevention.

- Protection of residents' right to health, including training for personal protective equipment and protocols to monitor the contagion of COVID-19 and for medical care.
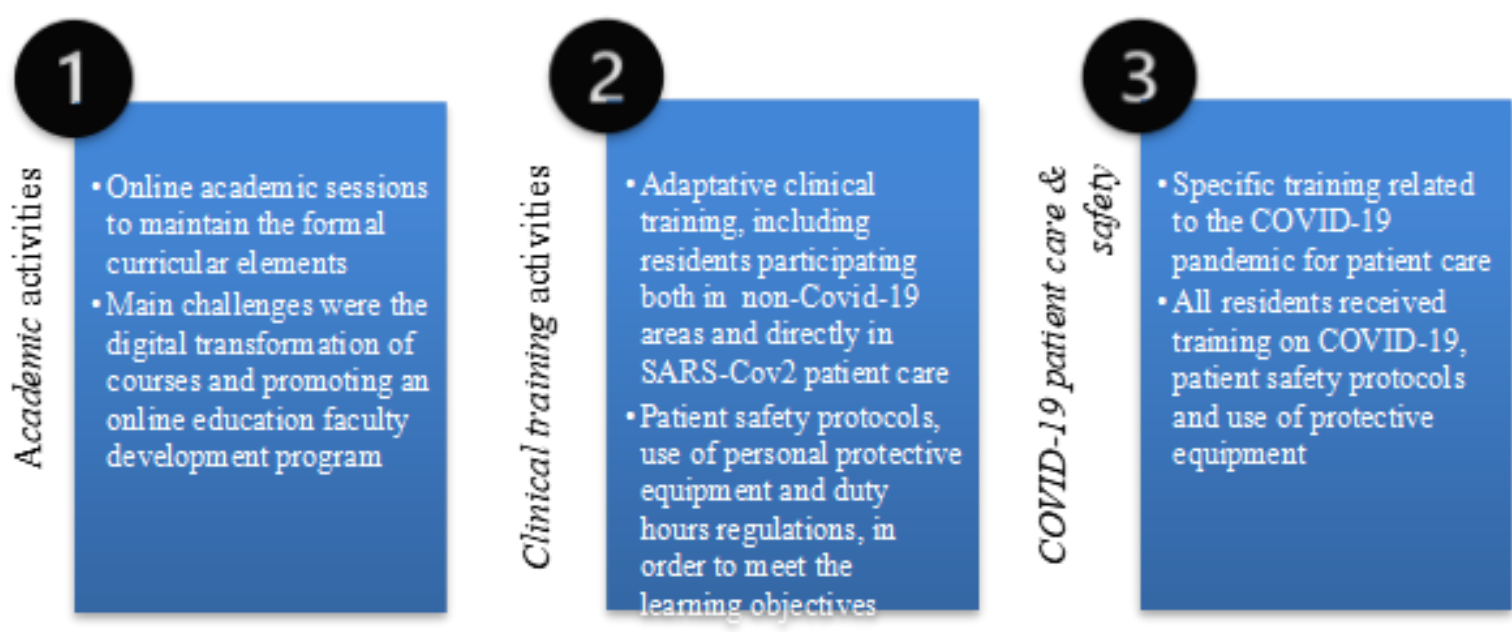

Professionalism and univer sity social responsibility actions implemented

Figure 1: Specific activities and social responsibility actions implemented with medical residents in 17 programs.

Additionally, the Professionalism and Wellbeing Program for Medical Residents implemented strategies since 2019 for the development of well-being as professional competence, to improve personal self-care, wellbeing, and patient care; a hybrid model was implemented due to the COVID19 pandemic from April 2020 to date.

The nature of the study is quantitative and descriptive. Data was gathered through the Office of Post graduate Medical Education and the Program Directors, through electronic files to register the academic activities, clinical training activities and the COVID-19 preventive measures and equipment provided to residents. The data related to the Professionalism and Wellbeing Program was obtained from the registration and attendance files for the activities offered to residents, and from the data 
gathered through the self-reported wellbeing and mentoring for residents follow-up electronic form. Microsoft Excel® was used to collect data and data analysis (Elliott et al. 2006).

\section{Results}

A comprehensive strategy to transform the Multicentric Program of postgraduate medical education to continue academic and clinical training activities amid the pandemic was designed and implemented during 2020 and 2021. The participants in this study include six training centers which represent 290 physicians in 17 medical specialties programs. Following are the results related to the comprehensive strategy and actions taken to guarantee academic continuity and clinical training in a Multicentric Program of postgraduate medical education amid the COVID-19 pandemic.

\section{Online academic sessions to maintain the formal curricular elements through educational platforms and electronic devices}

The results of the designed strategy focusing on the formal curricular elements offered through online platforms and mobile devices are presented in Table 1. During the march-august 2020 academic semester, $11(65 \%)$ of 17 programs did not miss any session, and $12(71 \%)$ of 17 programs in the september 2020-january 2021 academic semester did not miss any session. The top performance for academic continuity was observed in the medical residency program of Quality of Clinical Care, which did not miss an academic session neither on the March-August 2020 Academic Semester nor in the September 2020- January 2021 semester. On the other hand, Cardiology and Neurology reported the highest number of missed academic sessions. Nevertheless, Cardiology was also among the 3 programs with the highest number of extra-academic sessions.

Table 1: Number of academic sessions carried out, missed, and extra-academic sessions carried out in all the medical specialty programs

\begin{tabular}{|c|c|c|c|c|c|c|}
\hline \multirow[b]{2}{*}{$\begin{array}{l}\text { Medical } \\
\text { specialty } \\
\text { program }\end{array}$} & \multicolumn{2}{|c|}{$\begin{array}{l}\text { Number of academic } \\
\text { sessions carried out }\end{array}$} & \multicolumn{2}{|c|}{$\begin{array}{l}\text { Number of academic } \\
\text { sessions missed }\end{array}$} & \multicolumn{2}{|c|}{$\begin{array}{l}\text { Extra-academic sessions } \\
\text { carried out }\end{array}$} \\
\hline & $\begin{array}{l}\text { Academic } \\
\text { Semester } \\
\text { March- } \\
\text { August } \\
2020\end{array}$ & $\begin{array}{l}\text { Academic } \\
\text { Semester } \\
\text { September } \\
2020 \text { - } \\
\text { January } \\
2021\end{array}$ & $\begin{array}{l}\text { Academic } \\
\text { Semester } \\
\text { March - } \\
\text { August } \\
2020\end{array}$ & $\begin{array}{l}\text { Academic } \\
\text { Semester } \\
\text { September } \\
2020 \text { - } \\
\text { January } \\
2021\end{array}$ & $\begin{array}{l}\text { Academic } \\
\text { Semester } \\
\text { March - } \\
\text { August } \\
2020\end{array}$ & $\begin{array}{l}\text { Academic } \\
\text { Semester } \\
\text { September } \\
2020 \text { - } \\
\text { January } \\
2021\end{array}$ \\
\hline Anesthesiology & 96 & 96 & 0 & 0 & 52 & 48 \\
\hline Cardiology & 1 & 26 & 22 & 22 & 71 & 71 \\
\hline $\begin{array}{l}\text { Critical Care } \\
\text { Medicine }\end{array}$ & 24 & 24 & 0 & 0 & 26 & 5 \\
\hline General Surgery & 96 & 96 & 0 & 0 & 96 & 96 \\
\hline Geriatrics & 71 & 88 & 26 & 0 & 108 & 144 \\
\hline $\begin{array}{l}\text { Gynecology and } \\
\text { Obstetrics }\end{array}$ & 140 & 140 & 3 & 3 & 25 & 25 \\
\hline $\begin{array}{l}\text { Internal } \\
\text { Medicine }\end{array}$ & 85 & 81 & 13 & 13 & 73 & 73 \\
\hline Neonatology & 26 & 26 & 0 & 0 & 4 & 4 \\
\hline
\end{tabular}




\begin{tabular}{lllllll}
\hline Neurology & 46 & 70 & 50 & 26 & 4 & 3 \\
\hline Ophthalmology & 120 & 120 & 0 & 0 & 30 & 30 \\
\hline Pathology & 72 & 72 & 0 & 0 & 24 & 24 \\
\hline $\begin{array}{l}\text { Pediatric } \\
\text { Neurology }\end{array}$ & 168 & 88 & 0 & 0 & 25 & 30 \\
\hline Pediatrics & 64 & 75 & 0 & 0 & 71 & 106 \\
\hline Psychiatry & 105 & 95 & 10 & 5 & 22 & 17 \\
\hline $\begin{array}{l}\text { Quality of } \\
\text { Clinical Care }\end{array}$ & 240 & 240 & 0 & 0 & 4 & 4 \\
\hline Radiology & 120 & 120 & 0 & 0 & 48 & 48 \\
\hline Urology & 38 & 38 & 0 & 0 & 0 & 0 \\
\hline
\end{tabular}

Adaptative clinical training, including residents participating both in non-Covid-19 areas and directly in SARS-Cov2 patient care

The number of residents that have been participating directly in SARS-Cov2 patient care and specific specialty training has remained similar across the different months (Table 2). The first wave of the pandemic started in March 2020, and in June 2020 it was necessary in order to provide patient care to Covid-19 patients that residents from different programs were integrated to the medical teams in those areas. The residents of the programs that participated were divided in 2 areas. The residents from Critical Care Medicine, Internal Medicine, Geriatrics, Anesthesiology, Cardiology and Neurology participated with the health care teams in the critical care unit and intermediate critical care unit. Residents from the programs of Gynecology, Pediatrics, Neonatology, Ophthalmology, Surgery and Quality of Clinical Care residency programs worked in the general hospital area with the non-critical Covid-19 patients.

From June to September 2020 both areas were supported, and from October 2020 to date, the critical care unit was covered by residents and faculty. As it is shown in Table 2, this is the reason that since October, we have observed a decreasing number of residents in these teams. The total number of residents decreased also because we had 6 residents that resigned the program for different reasons.

Table 2: Number of medical residents in COVID and COVID-free areas

\begin{tabular}{llll}
\hline Month and year & $\begin{array}{l}\text { Number of } \\
\text { residents in COVID } \\
\text { areas }\end{array}$ & $\begin{array}{l}\text { Number of residents in } \\
\text { COVID-free areas }\end{array}$ & $\begin{array}{l}\text { Total number of medical } \\
\text { residents }\end{array}$ \\
\hline June 2020 & 90 & 200 & 290 \\
\hline July 2020 & 99 & 191 & 290 \\
\hline August 2020 & 104 & 185 & 289 \\
\hline September 2020 & 110 & 179 & 289 \\
\hline October 2020 & 78 & 210 & 288 \\
\hline November 2020 & 79 & 207 & 286 \\
\hline December 2020 & 77 & 209 & 286 \\
\hline January 2021 & 83 & 201 & 284 \\
\hline
\end{tabular}




\section{Specific training related to the COVID-19 pandemic for patient care}

Residents of all the 17 programs received training related to COVID-19, patient safety protocols, and use of protective equipment. The strategies to protect residents' right to health has included providing personal protective equipment, protocols to monitor the contagion of COVID-19, medical care if needed, and COVID-19 Vaccination (Table 3).

So far, 6520 N95 masks were distributed, and 443 face shields. Regarding the PCR tests strategy, 1119 tests have been done, from which 148 have resulted positive and 971 were negative. From the vaccine strategy, 272 of the 284 residents have been benefited. Residents received specific training on COVID-19, patient safety protocols, and the use of protective equipment.

Table 3: Deployed measures with medical residents to mitigate the spread of the virus

\begin{tabular}{lll}
\hline Measure & Description & Impact \\
\hline Personal protective & N95 masks & 6,520 \\
\cline { 2 - 3 } equipment & Face shield & 443 \\
\hline $\begin{array}{l}\text { PCR tests for } \\
\text { COVID-19 }\end{array}$ & Total number of tests & 1,119 \\
\cline { 2 - 3 } & Tests carried out due to change of hospital location & 667 \\
\cline { 2 - 3 } & $\begin{array}{l}\text { Tests performed for symptoms or contact with } \\
\text { positive cases }\end{array}$ & 452 \\
\hline Vaccine & Vaccinated residents (at least one shot) & $272 / 284$ \\
\hline
\end{tabular}

\section{Professionalism and university social responsibility actions: Professionalism and Wellbeing Program for Medical Residents}

Residents were offered mentoring and support services as strategies for self-care, well-being, mental health care, and burnout syndrome prevention. In February 2020, medical residents participated in the induction sessions of the Professionalism and Wellbeing Program, and at least in 3 sessions throughout the semester virtually. The chiefs and co-chiefs of residents were trained in a Workshop to help other residents in adverse situations.

Among the virtual strategies, we implemented an online website, an electronic form for residents' wellbeing and mentoring follow-up, individual virtual counseling, and Balint groups in Zoom. From April 2020 to January 2021, 148 residents registered their wellbeing and mentoring follow-up in the electronic form. The topics of greatest interest for discussion selected by the participants $(n=51)$ in the Balint group sessions were: emotional well-being (94.1\%) and burnout syndrome (94.1\%).

\section{Discussion}

The pandemic has posed many challenges for the academic continuity of clinical training in postgraduate medical education, underscoring the social responsibility of universities and the professionalism of medical residents in the front line of patient care in the era of the COVID-19 pandemic. The descriptive results of this comprehensive strategy to transform the Multicentric Program of postgraduate medical education to continue academic and clinical training activities amid 
the pandemic during 2020 and 2021, in six training centers, with 290 resident physicians in 17 medical specialties programs, are only a first approach to analyze the experience of an unexpected scenario and deeper analysis is required to assess its impact and effectiveness. However, relevant discussion topics can be initially addressed.

The involvement of medical residents in patient care while continuing their training in the COVID-19 pandemic has been a challenge. To successfully implement it, an action plan was followed in medical residency programs amid COVID-19 (Valdez et al. 2020). First, the protection and safety of the educational community were privileged with the purpose of training. It was achieved by providing residents specific safety training on COVID-19 and personal protection equipment (PPE, 6520 N95 masks and 443 face shields), performing periodical PCR testing (1119 tests) and by the vaccination strategy ( 272 of the 284 residents had been vaccinated).

Secondly, academic continuity was be performed with distance education, considering stages of preparation, design, implementation, and evaluation, by intensive use of technology, digital resources, and application of virtual simulation scenarios (Chick et al. 2020). All 17 programs achieved academic continuity by the use of digital platforms, such as Zoom and Canvas, and simulation exercises. A faculty development program for online education was accredited by faculty and was crucial to made possible the expedite transformation of all courses to an online version.

Third, communication, mentoring and emotional follow-up of the academic community were offered to mitigate the anxiety, uncertainty, and burnout. Residents were offered mentoring and support services, such as counseling and mental health services, as strategies for self-care, well-being, mental health care, and burnout syndrome prevention. All residents received direct support from their program director and chief residents. Among the virtual strategies for wellbeing and mentoring, we implemented an online website and an electronic form in which, from April 2020 to January 2021, 148 residents registered their wellbeing and mentoring follow-up.

Finally, social responsibility was fulfilled as part of the Medical and Health Sciences mission, including the responsibility of residents' safeguard, providing them personal protective equipment, and advocating for them to receive their immunization against COVID-19. In 2020, most residents participated in a session of the Wellbeing Program during an academic protected time. Most of the sessions were virtual during 2020 and more than half the residents registered the wellbeing program follow-up electronic form.

These initiatives strengthen the training processes of education, professionalism, and humanism as an expression of the social responsibility of the profession to contribute to residents' self-care, wellbeing, and patient care. Clinician well- being is a major challenge in health care, amid the pandemic it has been especially important to care for residents and faculty members. These well-being concerns continue to be compounded by the threat to physical safety occurring on the frontlines, therefore this strategy needed to integrate the need for PPE and vaccination (Byrne et al. 2021). 


\section{Study limitations, recommendations, and scope of future research}

The main study limitation was being only descriptive of the actions designed and implemented, and not including an assessment instrument, for example, a questionnaire for program directors and residents related to the impact and effectiveness of the comprehensive strategy.

Therefore, a next step to the research for the 2021 academic period will be to gather quantitative data by having a questionnaire on the effectiveness, appropriateness and applicability of the designed strategy and add indicators on the three.

For future research, residents' and chief residents' perception about challenges and recommendations for the future of postgraduate medical education amid the pandemic should be also explored (Rakowsky et al. 2020).

\section{Conclusion}

The COVID-19 pandemic highlighted fissures in health care and medical education systems, but it also delivered a glance of a future that will require prompt innovation when challenged in unpredictable times. This study described the challenging experience of the design and implementation of a comprehensive strategy to guarantee academic continuity and clinical training in a Multicentric Program of postgraduate medical education amid the COVID-19 pandemic. The results described that all 17 medical specialties programs were able to continue their academic and clinical activities. All 17 programs achieved academic continuity by the use of digital platforms. The protection and safety of the educational community were privileged with the purpose of training by providing residents specific safety training on COVID-19, personal protection equipment, periodical PCR testing and by the vaccination strategy.

However, future steps need to be taken to extend the transformation of the programs, not only as a contingency response, but also as an opportunity for medical residency programs to innovate and continue their transition from time-based to competency-based.

A relevant limitation of the study was not including an assessment instrument for program directors and residents related to the impact and effectiveness of the comprehensive strategy. An important next step to the research at the 2021 academic period will be to gather quantitative data by having a questionnaire on the effectiveness, appropriateness and applicability of the designed strategy and add indicators.

Postgraduate medical education has now an opportunity to evolve and envision its future (Simpson $e t$ al. 2020). The responsibility and responsiveness of educational institutions to address the challenges to continue the clinical training during the health crisis will significantly affect the educational results and preparedness of the next generation of health professionals. The commitment of universities should be beyond academic continuity or sharing content online, it should address self-care and wellbeing strategies as well, that could provide graduates with the skills that are essential to thrive in the current pandemic.

In the near future, new challenges and opportunities will shape the new era of postgraduate medical education (Rakowsky et al. 2020). For example, starting residency during a pandemic. What will 
change? What will stay the same? There are many unknowns in starting residency at any time, but experienced residents say one thing is clear from before and especially now: stress is unavoidable (Weiner, 2020). And therefore, it is also unavoidable the social responsibility of training programs and institutions to provide wellbeing programs and support services.

It is also time to think that the next step in this evolution of the pandemic is, as Goldhamer et al (2020) have suggested, a transition from time-based to competency-based, time-variable (CB-TV) GME, in which each physician graduates from residency when the required competencies by the program are achieved (Powell and Carraccio, 2018). Even if several factors and complacency about the status quo impede the implementation of CB-TV GME, Covid may propel us over the threshold. Because Covid's disruption to GME may continue - and because CB-TV GME has been a goal for educational reform - we should use this unexpected, uncontrolled experiment as an opportunity to learn how best to implement CB-TV GME.

Nowadays, our fundamental responsibility -and hope- may be that the Covid crisis will be used to capitalize on prior work and catalyze planning for a robust system achieving sustainable improvement in how we train physicians and how to emphasize self-care and well-being of health care professionals (Goldhamer et al. 2020). It is the end of an era.

\section{Acknowledgments}

The authors would like to acknowledge the financial support of Writing Lab, TecLabs, Tecnologico de Monterrey, Mexico, in the production of this work.

\section{References}

Accreditation Council for Graduate Medical Education. (2020). Three Stages of GME During the COVID-19 Pandemic. Retrieved from URL https://acgme.org/COVID-19/-Archived-Three-Stages-ofGME-During-the-COVID-19-Pandemic

American Medical Association. (2020). Guiding principles to protect resident and fellow physicians responding to COVID-19. Retrieved from URL https://www.ama-assn.org/deliveringcare/publichealth/guiding-principles-protect-resident-fellow-physicians-responding

Botros, M. \& Cooper, A. (2020). The Hidden Curriculum of the COVID-19 Pandemic. Journal of Graduate Medical Education, 12(5), 550-552. Retrieved from URL http://dx.doi.org/10.4300/JGMED-20-00502.1

Byrne, L., Holmboe, E., Kirk, L., \& Nasca, T. (2021). GME on the Frontlines-Health Impacts of COVID-19 Across ACGME-Accredited Programs. J Grad Med Educ, 13(1), 145-152. doi: https://doi.org/10.4300/JGME-D-20-01539.1

Chick, R.C., Clifton, G.T., Peace, K.M., Propper, B., Hale, D., Alseidi, A., Vreeland, T. (2020). Using technology to maintain the education of residents during the COVID-19 pandemic. J Surg Educ,77, 729-732. doi: https://doi.org/10.1016/j.jsurg.2020.03.018

Elliott, A.C., Hynan, L.S., Reisch, J.S., Smith, J. (2006). Preparing Data for Analysis Using Microsoft Excel. Journal of Investigative Medicine, 54, 334-341.

Goldhamer, E., Pusic, M., Patrick, J. \& Weinstein, D. (2020). Can Covid Catalyze an Educational Transformation? Competency-Based Advancement in a Crisis. NEJM, 383(11), 1003-1005. doi 10.1056/NEJMp2018570 
Powell, D.E. \& Carraccio, C. (2018). Toward competency-based medical education. $N$ Engl J Med, 378, 3-5.

Rakowsky, S., Flashner, B.M., Doolin, J., Reese, Z., Shpilsky, J., Yang, S., Smith, C., Graham, K. (2020). Five questions for residency leadership in the time of COVID-19: Reflections of chief medical residents from an internal medicine program. Acad Med, 95, 1152-1154. doi: 10.1097/ACM.0000000000003419

Simpson, D., Sullivan, G., Artino, A., Deiorio, N., Yarris,L. (2020). Envisioning Graduate Medical Education in 2030. J Grad Med Educ, 12(3), 235-240. doi: https://doi.org/10.4300/JGME-D-20$\underline{00292.1}$

Valdez-García, J.E., Eraña-Rojas, I.E., Díaz Elizondo, J.A., Cordero-Díaz, M.A., Torres-Quintanilla, A., Esperón-Hernández, R.I., Zeron-Gutiérrez, L. (2020). The role of the medicine student in COVID19 pandemic. A shared responsibility. Cir Cir, 88(4), 399-401. doi: 10.24875/CIRU.M20000066.

Valdez, J., López, M., Jiménez, M., Díaz Elizondo, J.A., Dávila Rivas, J.A., Olivares, S. (2020). Preparing to help: response strategy of schools of medicine and health sciences to COVID-19 pandemic [Me preparo para ayudar: respuesta de escuelas de medicina y ciencias de la salud ante COVID-19]. Inv Ed Med., 9, 1-11. Retrieved from URL https://doi.org/10.22201/facmed.20075057e.2020.35.20230

Vande Vusse, L., Ryder, H., \& Best, J. (2021). Maximizing Career Advancement During the COVID19 Pandemic: Recommendations for Postgraduate Training Programs. Academic medicine : journal of the Association of American Medical Colleges, 10.1097/ACM.0000000000003938. Advance online publication. Retrieved from URL https://doi.org/10.1097/ACM.0000000000003938

Weiner, S. (2020). Starting residency during a pandemic: What will change? What will stay the same? [News]. Association of American Medical Colleges. Retrieved from URL https://www.aamc.org/news-insights/starting-residency-during-pandemic-what-will-change-whatwill-stay-same 